\title{
The Influence of Subinertial Internal Tides on Near-Topographic Turbulence at the Mendocino Ridge: Observations and Modeling $\mathscr{O}$
}

\author{
R. C. Musgrave, J. A. Mackinnon, R. Pinkel, and A. F. Waterhouse \\ Scripps Institution of Oceanography, University of California, San Diego, La Jolla, California
}

J. NASH

Oregon State University, Corvallis, Oregon

S. M. KELLY

University of Minnesota Duluth, Duluth, Minnesota

(Manuscript received 19 December 2016, in final form 5 June 2017)

\begin{abstract}
Shipboard measurements of velocity and density were obtained in the vicinity of a small channel in the Mendocino Ridge, where flows were predominantly tidal. Measured daily inequalities in transport are much greater than those predicted by a barotropic tide model, with the strongest transport associated with full depth flows and the weakest with shallow, surface-confined flows. A regional numerical model of the area finds that the subinertial $\mathrm{K}_{1}$ (diurnal) tidal constituent generates topographically trapped waves that propagate anticyclonically around the ridge and are associated with enhanced near-topographic $\mathrm{K}_{1}$ transports. The interaction of the baroclinic trapped waves with the surface tide produces a tidal flow whose northward transports alternate between being surface confined and full depth. Full depth flows are associated with the generation of a large-amplitude tidal lee wave on the northward face of the ridge, while surface-confined flows are largely nonturbulent. The regional model demonstrates that, consistent with field observations, near-topographic dissipation over the entire ridge is diurnally modulated, despite the semidiurnal tidal constituent having larger barotropic velocities. It is concluded that at this location it is the bottom-trapped subinertial internal tide that governs near-topographic dissipation and mixing. The effect of the trapped wave on regional energetics is to increase the fraction of converted barotropic-baroclinic tidal energy that dissipates locally.
\end{abstract}

\section{Introduction}

The interaction of the barotropic tide with topography gives rise to a range of phenomena, including the generation of an internal tide that propagates large distances across the ocean, transferring energy out of the surface tide where it is generated and dissipating that energy via turbulence where the internal tide breaks or shoals. Where the tide has a frequency lower than the local Coriolis frequency, internal tides are unable to freely radiate and instead may take the form of

Supplemental information related to this paper is available at the Journals Online website: http://dx.doi.org/10.1175/JPO-D-160278.s1.

Corresponding author: R. C. Musgrave, rmusg@mit.edu topographically trapped waves, leading to locally enhanced subinertial tidal transports (Huthnance 1974; Chapman 1989; Brink 1990; Padman et al. 1992). The generation of turbulence and mixing by internal tides, trapped or otherwise, modifies water masses and influences the stratification of the ocean on both regional and global scales. Close to topography, turbulence has been observed to arise from breaking tidal lee waves and hydraulic jumps, as the stratified ocean accelerates over submerged ridges (Klymak et al. 2008; Nakamura et al. 2010). However, of the energy converted from the barotropic tide to baroclinic motions, estimates of the fraction of energy that dissipates via processes such as these is widely variable by region, ranging from up to $15 \%$ at Hawaii (Klymak et al. 2006), up to $40 \%$ at the Luzon Strait (Alford et al. 2015), and up to 70\% in the high-latitude Bering Sea (Tanaka et al. 2013). 
In a baroclinic global tide model, Müller (2013) found that $30 \%$ of the energy in the global diurnal barotropic tide dissipates poleward of $30^{\circ}$, where it is subinertial and cannot generate freely propagating internal tides. This energy input into relatively high-latitude oceans dissipates close to where the barotropic tide loses energy, potentially leading to near-topographic mixing at relatively enhanced levels compared to low latitudes. Understanding the processes that lead to this regional variability in tidal mixing is an important problem as these small-scale phenomena cannot be resolved in global climate models, and as such their effects must be parameterized (Green and Nycander 2013).

The near-field dissipation characteristics of subinertial and superinertial baroclinic tides were considered in a numerical study by Tanaka et al. (2013) in the Bering Sea, where the diurnal $\left(\mathrm{K}_{1}\right)$ constituent is subinertial and the semidiurnal $\left(\mathrm{M}_{2}\right)$ constituent is superinertial. They found that dissipation associated with the $\mathrm{K}_{1}$ constituent was localized near the shelf break, while dissipation associated with $\mathrm{M}_{2}$ occurred both at the shelf break and high in the water column, associated with the freely radiating internal tide. Idealized two-dimensional simulations of tidal flow over a Gaussian ridge support this result, showing that mixing in subinertial tidal flows arises through hydraulic jumps on the flanks of topography, while mixing in superinertial tidal flows also occurs through breaking tidal lee waves aloft (Musgrave et al. 2016b). However, the inherent nonlinearity of phenomena that lead to turbulence suggests that the presence of more than one tidal constituent may influence the magnitudes and spatial structure of near-field turbulence in a way that is not simply a superposition of the dissipation associated with individual constituents.

In an earlier study we presented observations and modeling of the processes leading to turbulence at the Mendocino Ridge where the $\mathrm{K}_{1}$ constituent generates a trapped internal tide and the $\mathrm{M}_{2}$ constituent generates a freely radiating tide (Musgrave et al. 2016a, hereinafter M16). In and around a relatively small channel crossing the crest of the ridge (see region of observations indicated in Fig. 1b), we found that tidally driven lee waves and hydraulic jumps formed on the flanks of the ridge downstream of the channel, leading to peaks in depthintegrated dissipation rates of up to $60 \mathrm{Wm}^{-2}$. This small, three-dimensional saddle feature in the crest of a predominantly two-dimensional ridge was the site of extremely large (around $1 \mathrm{~m} \mathrm{~s}^{-1}$ ) tidal currents, with a diurnal inequality in the amplitude of the tides. Motivation for the present work arose from the observation that tidal lee waves only formed once per day after the strongest of the daily peaks, despite the presence of two daily peaks. During the weaker beat of the tide, tidal transport was accommodated in a surface layer, with largely quiescent flow at depth close to topography-a vertical structure that is not predicted for single-frequency tidal flows at any latitude. Here, we study the dynamics that lead to the observed distinct characters of adjacent peak tides by running a regional tidal model for the area and examining the interaction of the tidal constituents at the ridge crest. We find that the different baroclinic structures of the subinertial and superinertial tidal constituents superpose at the crest of the ridge to determine the timing and location of tidally driven turbulence in our observations.

The remainder of this paper is divided into four parts. In sections 2 and 3 we describe the observations and regional model used to interpret the observations, respectively. In section 4 we discuss the dynamics of the tidal flows through the channel and over the ridge, illustrate the presence of trapped subinertial internal tides, and examine their influence on the modeled baroclinic energy budget. We also look at the timing and spatial structure of the modeled dissipation rates, as well as discuss the presence of tidally rectified flows in our model. Finally, in section 5 we summarize our findings.

\section{Observations}

In November 2012, a series of ship-based measurements of velocity and density were obtained in the vicinity of a small channel incising the crest of the Mendocino Ridge in the eastern Pacific. The site is located where the ridge intersects the North American continental shelf at a latitude of around $40^{\circ} \mathrm{N}$ (Fig. 1). Observations are described in detail in M16, and here we provide a summary with an emphasis on the measurements that motivate this paper. Four stations were occupied for 24-30h, two stations to the north of the channel ( $\mathrm{C} 1$ and $\mathrm{C} 2)$ and two shallower stations atop the ridge crest on the west flank of the channel (R1 and R2). At each location, the ship held position while a CTD and lowered acoustic Doppler current profiler (LADCP) package was repeatedly yo-yoed the full depth of the water column. In this manner, continuous depth time series of velocity and density were obtained. Isopycnals and along-channel velocities (rotated clockwise $17^{\circ}$ from north) are shown in color in the insets in Fig. 1b: (i) R1 and $\mathrm{R} 2$ and (ii) $\mathrm{C} 1$ and $\mathrm{C} 2$. The diurnal inequality is especially clear in the channel (stations $\mathrm{C} 1$ and $\mathrm{C} 2$ ), where alternate northward tides are either surface confined or extend to full depth. A similar pattern occurs over the adjacent ridge, though peak transports and dissipation rates are smaller (not shown). Measured 

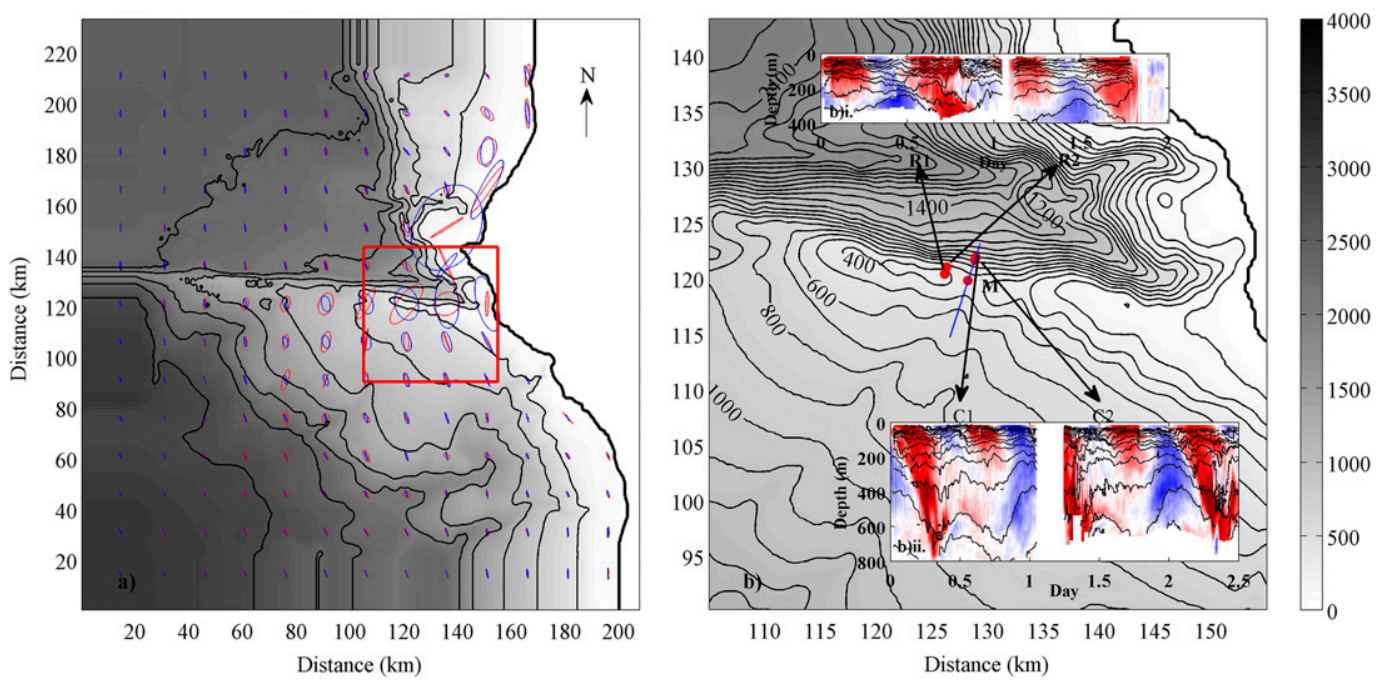

FIG. 1. (a) Bathymetry over the full computational domain; contours are every $500 \mathrm{~m}$. The geographic region is the easternmost extent of the Mendocino Ridge in the eastern Pacific, at a latitude of around $40^{\circ} \mathrm{N}$. Blue tidal ellipses are TPXO predictions for the barotropic $\mathrm{K}_{1}$ constituent, and red ellipses are the barotropic $\mathrm{K}_{1}$ constituent from tidal regional model. (b) Inset [red box in (a)] showing the crest of the ridge and small channel where observations (red dots) were obtained. Cross-ridge velocity time series from four stations are shown in insets with isopycnals contoured in black, and red/blue indicating northward/southward flow, respectively, with colors saturating at $\pm 1 \mathrm{~m} \mathrm{~s}^{-1}$.

turbulent dissipation rates in the channel are elevated by two orders of magnitude just after the full-depth flows, but have no elevation during the weaker, surfaceconfined northward flows (not shown, see M16).

A mooring was in place for 10 days at the center of the channel, and the along-channel velocities (color) and isopycnals (contoured) are shown in Fig. 2b. As for the stations on the flanks of the ridge, the diurnal inequality in the channel is strong, and its signature is emphasized in the depth-integrated along-channel transports shown in blue in Fig. 2c. During the strong beat of the tide, transports reach up to $500 \mathrm{~m}^{2} \mathrm{~s}^{-1}$, corresponding to a depth-averaged velocity of $1 \mathrm{~m} \mathrm{~s}^{-1}$. Tidal transports at this location predicted by the Oregon State University TOPEX/Poseidon Global Inverse Solution tidal model (TPXO; Egbert and Erofeeva 2002) are shown in the same panel in black and demonstrate good agreement with the phase of the flows but poor agreement with the amplitude, especially during the strong beat of the tide. TPXO uses satellite altimetry to constrain solutions to the shallow water Laplace tidal equations on a $1 / 30^{\circ}$ bathymetric grid (about $3 \mathrm{~km}$ at this latitude).

Depth-integrated dissipation rates at the mooring were estimated following the method outlined in Zhang and Moum (2010), using time series of 1-Hz temperature loggers that were vertically spaced approximately every $20 \mathrm{~m}$. These are shown in blue in Fig. 2d, where peaks in dissipation rates occur just after the largest southward and northward flows of the day and are associated with the advection past the mooring of tidal lee waves and hydraulic jumps that form on the southern and northern flanks of the ridge. These phenomena were explored in detail in M16 with the aid of a high-resolution, two-dimensional, nonhydrostatic model.

During the weak beat of the tide, transports through the channel are much smaller, and depth time series from the stations and mooring illustrate a distinctly different nature to the flow at these times (Fig. 2b). While the strong beat of the tide is associated with fulldepth, bottom-intensified flows, the transport during weak northward flows is accommodated almost entirely at the surface, with weak, almost reversed flows close to the crest of the ridge. A two-dimensional analysis based only on the barotropic transport such as that employed by Farmer and Smith (1980) and Klymak et al. (2010) over tall topography would suggest that lee waves should form even during the weak beat of the tide, simply having a shorter vertical scale corresponding to the trapping of slower (higher) vertical modes at the ridge crest. However, our observations show that during this phase of the tide no tidal lee waves or hydraulic jumps form, and it is clear that the flow does not simply correspond to a weaker version of strong northward flows. Understanding the baroclinic structure of this weak beat of the tide is one of the main research questions that we address in this paper, and answering it involves an understanding of the regional-scale flows in the vicinity of the ridge crest. 


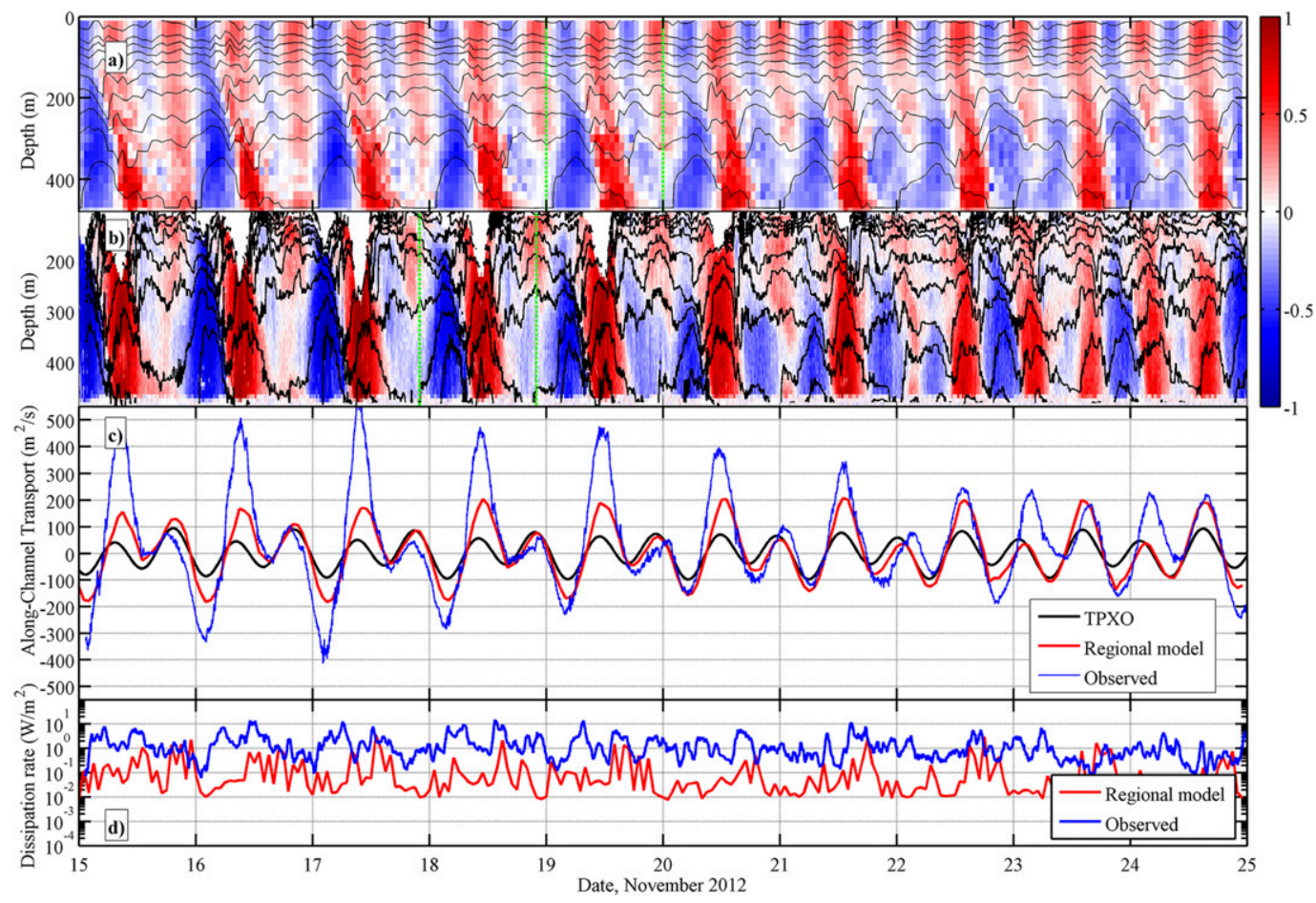

FIG. 2. (a) Modeled and (b) observed cross-channel velocity time series at the mooring [red, northward; blue, southward $\left(\mathrm{m} \mathrm{s}^{-1}\right)$ ]. Isopycnals contoured. Green dashed lines indicate times when the shallow beat of the tide is reproduced by simulated flows. (c) Transports at the mooring from observations (blue), regional model (red), and TPXO predictions (black). (d) Depth-integrated dissipation rates at the mooring from observations (blue) and from regional model (red).

\section{Numerical simulations}

\section{a. Model configuration}

We used the hydrostatic MITgcm (evolved from Marshall et al. 1997) to run three different regional tide simulations in the vicinity of the observations using the barotropic flows predicted by TPXO. In the first simulation we forced the model with only the $\mathrm{K}_{1}$ constituent of the tide (the $\mathrm{K}_{1}$-only run); in the second we forced only with the $\mathrm{M}_{2}$ constituent (the $\mathrm{M}_{2}$-only run); and in the third we used both the $\mathrm{K}_{1}$ and $\mathrm{M}_{2}$ tidal constituents to generate the model forcing (the $\mathrm{K}_{1}+\mathrm{M}_{2}$ run). We used a horizontally uniform density profile, with a vertical stratification derived from CTD profiles obtained on the Oregon continental shelf (Martini et al. 2011). Density in the model is determined entirely by temperature using a linear equation of state. The domain was approximately $200 \mathrm{~km} \times 200 \mathrm{~km}$ in size with the outer $30 \mathrm{~km}$ of ocean boundary constituting the forcing/ sponging region. Within this region, the model was forced by nudging the variables toward the TPXOpredicted barotropic values using expressions such as

$$
\mathcal{G}_{u}=\frac{1}{\tau}\left(u_{i j}-u_{\mathrm{TPXO}}\right),
$$

where $\mathcal{G}_{u}$ is the forcing applied to the $x$-momentum equation, $u_{i j}$ is the horizontal velocity at that grid point, $u_{\text {TPXO }}$ is the TPXO predicted value, and $\tau$ is a time scale that takes a value of $4 \mathrm{~h}$ at the inner boundary and $10 \mathrm{~min}$ at the outer boundary. In this manner, baroclinic signals are increasingly strongly damped as they propagate outwards, without a sudden change that could reflect baroclinic energy back into the domain (Carter and Merrifield 2007). Grid resolution in the domain interior is $300 \mathrm{~m}$ in the horizontal and $20 \mathrm{~m}$ above $2000 \mathrm{~m}$ depth in the vertical, telescoping to $46 \mathrm{~m}$ at depth. Model bathymetry is taken from $70 \mathrm{~m} \times 90 \mathrm{~m}$ gridded multibeam bathymetry extracted from the NOAA database (https://maps.ngdc.noaa.gov/viewers/bathymetry/). The full model domain is shown in Fig. 1a, with the detailed bathymetry of the near-channel region shown in Fig. 1b. The $\mathrm{M}_{2}$-only and $\mathrm{K}_{1}$-only runs were spun up for nine and four periods, respectively, before any analysis was performed. The $\mathrm{K}_{1}+\mathrm{M}_{2}$ run was integrated for the period from 10 to 25 November 2012, with the forcing linearly ramped up from zero over the first day to reduce transient effects. The first five days are considered to be a part of the model spinup and are excluded from all analysis. Snapshot fields of velocity, temperature (related to density by a linear equation of state), and 
parameterized dissipation rate for the whole domain were output hourly in all simulations. The MITgcm employs a second-order centered advection scheme for momentum, and we used a one-step, seventh-order, monotonicity-preserving advection scheme for temperature (Daru and Tenaud 2004).

Subgrid-scale mixing was parameterized using the scheme described by Klymak and Legg (2010), which calculates an enhanced viscosity and diffusivity up to a value of $300 \mathrm{~m}^{2} \mathrm{~s}^{-1}$ by Thorpe sorting in regions of static instability and setting the diffusivity by inferring the dissipation rate and using a fixed mixing efficiency. This helps to maintain numerical stability by rapidly removing overturns while estimating the kinetic energy that would be dissipated by overturns of this scale in the ocean. The use of Klymak and Legg (2010) in tidally driven simulations has been shown to reduce numerical dissipation compared to a constant background viscosity, as a greater fraction of the dissipation is handled explicitly by the overturn scheme (Buijsman et al. 2012). Background diffusivities and viscosities are chosen to maintain model stability and suppress noise. We used isotropic diffusivities of $\kappa_{H}=\kappa_{z}=1 \times 10^{-4} \mathrm{~m}^{2} \mathrm{~s}^{-1}$ and anisotropic viscosities of $\nu_{H}=5 \times 10^{-1} \mathrm{~m}^{2} \mathrm{~s}^{-1}$ and $\nu_{z}=$ $1 \times 10^{-3} \mathrm{~m}^{2} \mathrm{~s}^{-1}$. They are comparable to those employed by Kang and Fringer (2012) $\left(\nu_{H}=1 \mathrm{~m}^{2} \mathrm{~s}^{-1}\right.$, $\left.\nu_{v}=5 \times 10^{-3} \mathrm{~m}^{2} \mathrm{~s}^{-1}\right)$ in a similar simulation of baroclinic tides in Monterey Bay. Quadratic bottom drag was applied at the boundary with a drag coefficient of $C_{d}=$ 0.002 to represent a turbulent boundary layer. The model was configured with a linear free surface, and free slip (no stress) conditions were imposed at topographic boundaries.

\section{b. Model comparison with TPXO and observations}

A comparison of the $K_{1}$ tidal ellipses from the $K_{1}+$ $\mathrm{M}_{2}$ run and TPXO are shown in red and blue in Fig. 1a. $\mathrm{K}_{1}$ ellipses were extracted from the simulated barotropic velocity time series after the model had spun up, by harmonic fit to the $\mathrm{K}_{1}$ frequency. Near the boundaries, the simulation closely reproduces TPXO tidal ellipses; however, in the vicinity of the ridge crest, discrepancies between the simulated and TPXO-predicted tides are present. A comparison of $\mathrm{M}_{2}$ tidal ellipses shows similar agreement away from and discrepancies close to the ridge crest (not shown). Differences between barotropic tidal flows in TPXO and our regional simulation are expected: TPXO assimilates satellite data to constrain solutions to the unstratified Laplace tidal equations on basin scales, with the astronomical potential-generating barotropic Kelvin waves that propagate on basin boundaries. In contrast, as the domain of our stratified simulation covers a region that is significantly smaller than the wavelength of a Kelvin wave, we do not include an astronomical potential, nor explicitly model the tidal Kelvin wave. Instead, we force the simulation at the boundaries by the barotropic tidal flows inferred from TPXO, with flows being otherwise unforced and unconstrained in the interior. In addition, the inclusion of stratification and a significantly higher-resolution bathymetry than TPXO may strongly influence tidal flows in the topographically complex region of the channel.

The along-channel tidal transport at the center of the channel predicted for the $K_{1}$ and $M_{2}$ constituents in TPXO and the $\mathrm{K}_{1}+\mathrm{M}_{2}$ run are shown as black and red lines in Fig. 2c. While the timings of northward and southward flows approximately match, the magnitude of the transport is between 2 and 3 times greater in the regional simulation than in TPXO and more closely agrees with observations. In addition, the phase of the $\mathrm{K}_{1}$ transport is shifted by $12 \mathrm{~h}$ so that the timing of the strongest beat of the tide occurs earlier in the day in the first part of the time series in the regional simulation compared to TPXO, bringing our simulation into better agreement with the observations. Large transports close to bathymetry associated with subinertial tidal constituents have been observed in places like the Yermak Plateau (Padman et al. 1992) and Fieberling Guyot (Kunze and Toole 1997) and are attributed to topographically trapped waves. As we do not include the $S_{2}$ tidal constituent, we do not reproduce the observed spring-neap cycle in our simulation. TPXO tidal predictions in the region of the channel indicate that during spring tide, currents would be around $40 \%$ larger than in our $\mathrm{K}_{1}+\mathrm{M}_{2}$ run.

The simulated depth time series from the center of the channel is shown in Fig. 2a. Timings of the strongest beat of the daily tide agree well with observations, but the vertical structure of the weaker beat of the tide is not well reproduced until later in the time series. As the two dominant tidal constituents are not integer multiples of one another, we expect a slow modulation of the amplitude envelope: for these two well-separated constituents there is a modulation at around 13.5 days. The phase of this slow modulation is sensitive to the phase of the component constituents, and so we attribute the shift between the observations and our simulation to errors in the modeled phase of the internal tide. Possible reasons for this are discussed below. This slow modulation of the tidal amplitudes manifests in our time series most clearly as changes in the baroclinic structure during the weak beat of the northward tide, which evolves over the 10 days of the simulation, from full depth from 15 to 18 November to increasingly surface confined by 22 November, where it reaches only to depths around $300 \mathrm{~m}$. After 22 November, the depth of the northward 
flow during the weak beat of the tide increases slightly with time. This slow evolution is also present in the observations, though with a 1-2-day time shift with respect to the model, with the shallowest observed northward flows during the weak beat of the tide occurring on 18 and 19 November, after which they gradually deepen, becoming full depth by 22 November. We find that the baroclinic structure of observed flows between $22 \mathrm{~h} 18-19$ November is well matched by simulated flows between 19 and 20 November (green dashed lines in Figs. 2a,b).

The key observation of surface-confined northward tidal transport during the weak beat of the northward tide is reproduced by the model around 19 November, when the amplitude of the daily inequality in the regional simulation is large. As such, it is the structure of the flows around this time that will be examined in the next section.

In summary, we find that the simulation provides an improvement in the predicted transports through the ridge over the barotropic and relatively lower-resolution TPXO model and is able to reproduce the observed baroclinic flow structures. However, discrepancies between the model and observations remain in the relative phase of the $\mathrm{K}_{1}$ and $\mathrm{M}_{2}$ constituents and the magnitude of the along-channel transports. The discrepancy in magnitude is larger during spring tide, but TPXO predictions for the region do not suggest that including more tidal constituents would account for the difference. Variations of the model configuration described above were run, including the second-largest diurnal tidal constituent, $\mathrm{O}_{1}$, and removing the quadratic bottom drag; however, they had only a small influence on the channel transports and did not fully account for the discrepancy between our observations and the model. In addition to those mentioned, other factors that may be responsible for these discrepancies include the presence of nontidal diurnal variability in the ocean (such as a diurnal sea breeze) or errors in the magnitude and phase of the TPXO boundary conditions, which is optimized over a much larger domain. Trapped waves are eigenmodes of the topography and background stratification, and consequently their phase speeds are sensitive to variability in the stratification or errors in the model bathymetry, which would also manifest as phase discrepancies between the model and observations. Furthermore, our geographical restriction of the numerical domain means that tidally driven continental shelf waves generated south of the southern boundary are excluded from our analysis, and these could plausibly influence the phase and amplitude of flows at the analysis region. Notwithstanding these differences, we find that the processes in the regional model are able to represent qualitatively the strong daily inequalities in the tide, its vertical structure in the channel, and the timing of the turbulence, and these are the subject of our investigation.

\section{Model interpretation and discussion}

\section{a. The baroclinic harmonic constituents: Radiating $M_{2}$ and trapped $K_{1}$ tides}

At this latitude we expect that the $\mathrm{M}_{2}$ constituent will generate internal tides that can freely propagate into the open ocean, while the subinertial $\mathrm{K}_{1}$ constituent will generate baroclinic motions that are trapped to the topography. The precise nature of the trapped subinertial response depends sensitively on the stratification and bathymetry (Brink 1989). If the eigenmodes of the topography have frequencies that are close to $\mathrm{K}_{1}$, then a resonance between the topographic modes and the tidal forcing can excite topographic waves that propagate along bathymetric contours (Chapman 1989; Brink 1990). Even in the absence of a resonance, the subinertial baroclinic response may be more energetic than a superinertial response close to the bathymetry, while still evanescent in the direction away from topography (Musgrave et al. 2016b).

A harmonic reconstruction of isopycnal displacements associated with the diurnal constituent is shown in Fig. 3, where red contours indicate downward isopycnal displacement and blue contours indicate upward displacement. Large isopycnal displacements occur close to topography, with structures that illustrate the baroclinic trapped waves as they propagate along the steep bathymetry. Isopycnal displacements that are directly associated with the barotropic tide are typically much smaller than that associated with the baroclinic tide $(<1 \mathrm{~m}$ at the surface, and decreasing with depth) and consequently are not apparent in Fig. 3. For steplike, vertical bathymetry, the baroclinic trapped waves formally become internal Kelvin waves (Rhines 1970) and have a vertically modal structure between the top and bottom of the step. In a similar manner to open-ocean superinertial internal waves, the superposition of the modes forms beams: coherent sloping structures trapped close to the bathymetry. As time progresses, phase moves down in the upward radiating beams and up in the downward radiating beams. Phase progression is more easily observed in the animation of one period of the trapped wave evolution, which is included in the supplementary material.

On the southern flank of the ridge, the shallower topographic slope compared to the northern face of the ridge changes the structure of the trapped wave modes, illustrating the sensitivity of these waves to changes in 


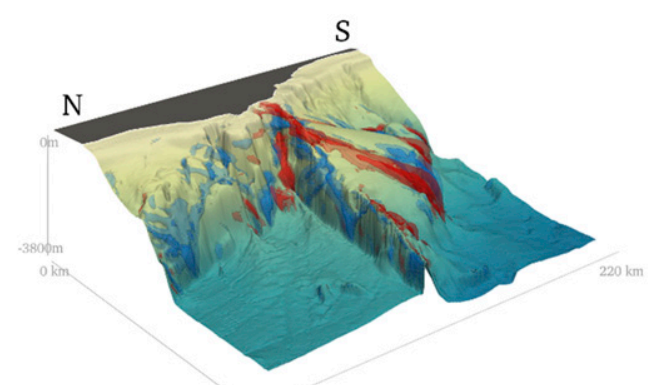

Time: $0 \mathrm{hr}$

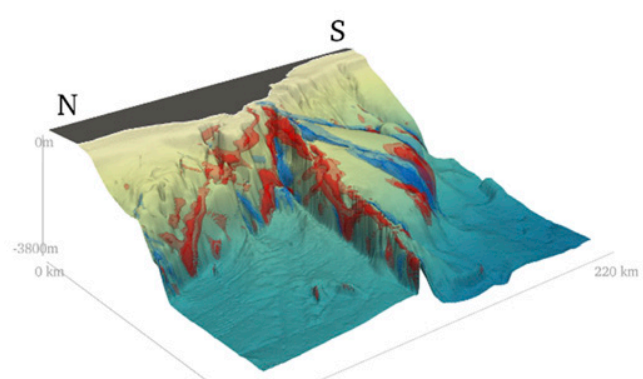

Time: $8 \mathrm{hr}$

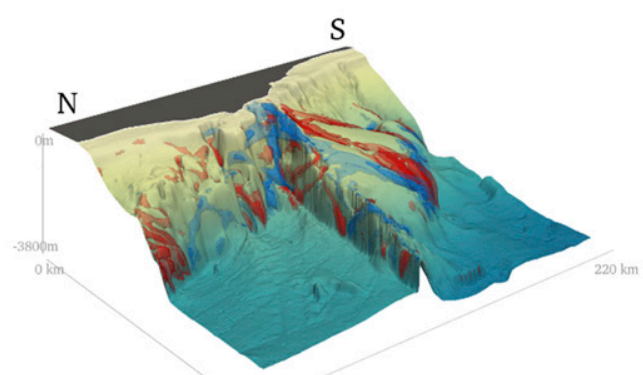

Time: $16 \mathrm{hr}$

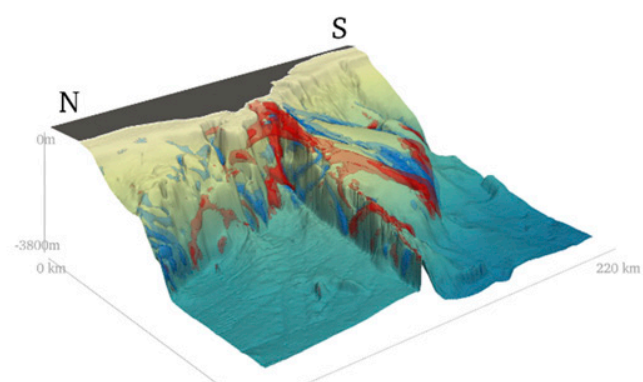

Time: $4 \mathrm{hr}$

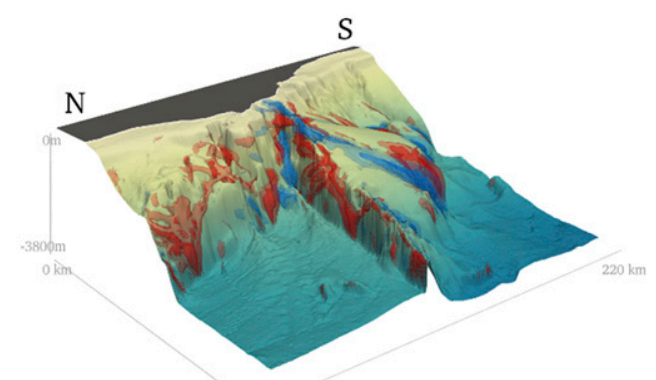

Time: $12 \mathrm{hr}$

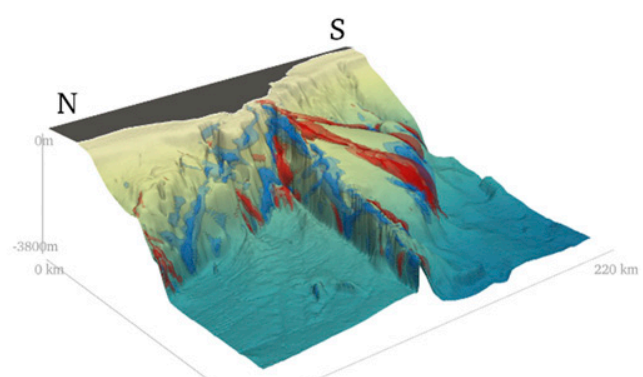

Time: $20 \mathrm{hr}$

FIG. 3. The $\pm 15 \mathrm{~m}$ isopycnal displacements from the $\mathrm{K}_{1}$-only simulation. Upward displacements of fluid are shaded in blue and downward displacements in red. Note that isopycnal displacements are trapped to the topography. The progression of the wave can be seen by comparing subsequent snapshots (left to right) in each of the rows, but are much easier to see in the movie of these images in the supplemental material. Beamlike structures are visible to the north of the domain.

topographic slope. The amplitude of trapped displacements around the western region of the domain is small, suggesting that deep trapped wave energy on the southern flank of the ridge is not fluxed north around the ridge. Maps of flux and modeled dissipation shown in section $4 \mathrm{c}$ confirm that trapped wave fluxes exhibit convergences where the topographic steepness and slope direction changes and are consistent with locations of enhanced modeled dissipation.

\section{b. Diurnal trapped waves and their influence on turbulence in the channel}

The observed daily inequality in the strength of the transport through the channel arises from a simple sum of tidal constituents at the $\mathrm{K}_{1}$ and $\mathrm{M}_{2}$ frequencies. At roughly alternate 12 -h intervals, the two constituents will either constructively or destructively superpose (leading to the strong and weak daily beats of the tide, respectively). However, it is the baroclinic structure of the flows associated with these constituents that determines the formation of tidal lee waves and their associated turbulence.

We compute reconstructions of the $\mathrm{K}_{1}$ and $\mathrm{M}_{2}$ harmonic components in along-channel sections at $12-\mathrm{h}$ separated intervals corresponding to northward flows on 19 November 2012 (Fig. 4), when the modeled transports have a similar vertical structure as our observations (i.e., strong daily inequalities). The first northward 

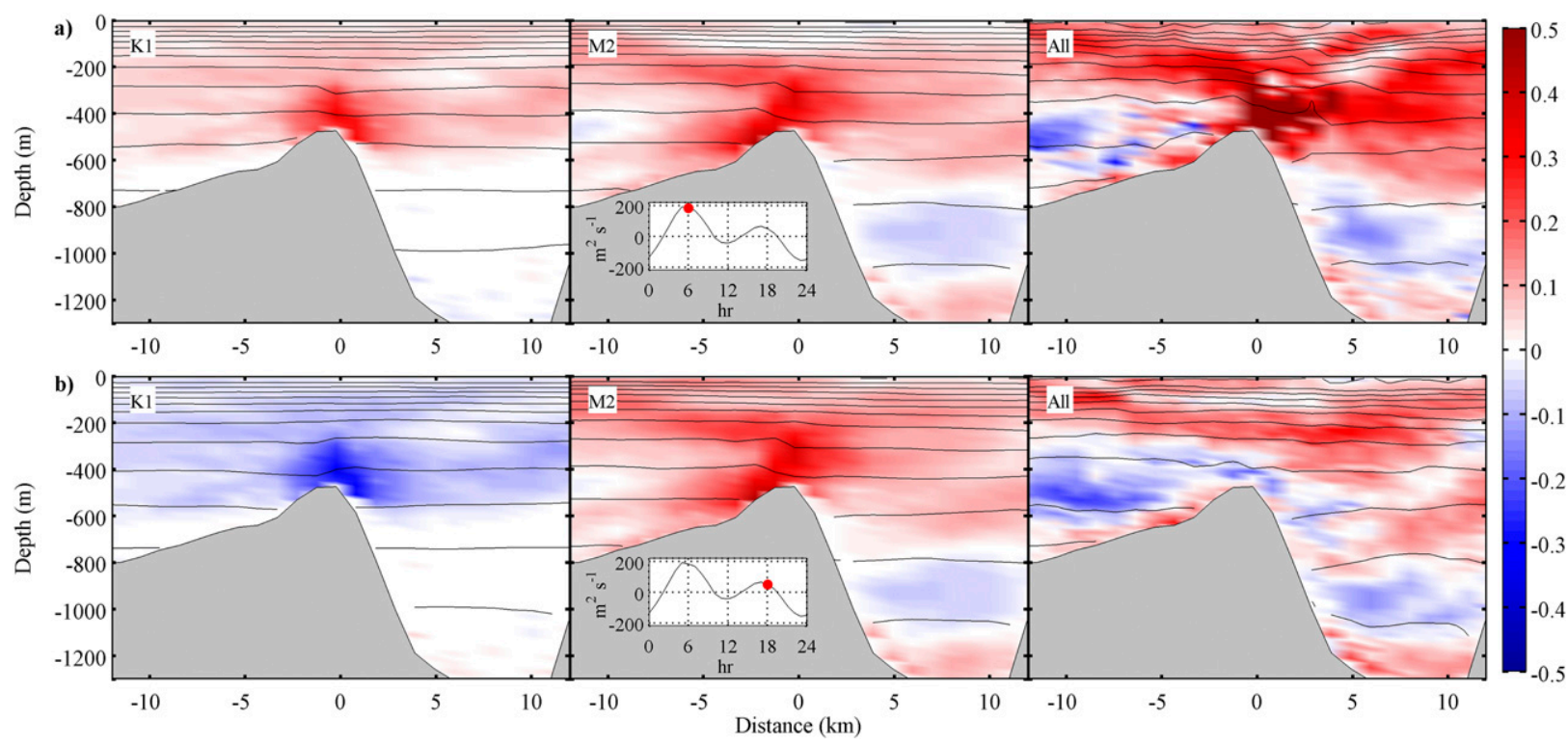

FIG. 4. Modeled $\mathrm{K}_{1}, \mathrm{M}_{2}$, and full along-channel velocity component, $12 \mathrm{~h}$ apart (upper and lower panels) on 19 November. Colors are velocity [red, northward; blue, southward $\left(\mathrm{m} \mathrm{s}^{-1}\right)$ ], isopycnals in black contours. Gray shading indicates topography through the channel. Insets show the barotropic transport time series through the channel, with the red dot indicating the time of the snapshot.

flow (Fig. 4a) corresponds to the strong beat of the tide, when both the $\mathrm{K}_{1}$ and $\mathrm{M}_{2}$ constituents have a northward transport. The baroclinic structure of the $\mathrm{K}_{1}$ constituent is topographically trapped with a northward flow that is strongly bottom enhanced, consistent with a trapped wave. The full flow (which is a sum of not only the $\mathrm{K}_{1}$ and $\mathrm{M}_{2}$ constituents, but also all other frequencies) exhibits northward velocity at all depths and precedes the generation of a large-amplitude tidal lee wave and large parameterized mixing in the model just after peak flow. Twelve hours later, the $\mathrm{K}_{1}$ tidal constituent is associated with a southward flow, and the $\mathrm{M}_{2}$ constituent is northward. As the southward $\mathrm{K}_{1}$ constituent is bottom trapped, the transport of the resulting net-northward flow is entirely accommodated in a surface layer that does not directly interact with the ridge crest. As a result, no lee wave is generated during this phase of the tide, and there is very little turbulence.

Though the generation of turbulence itself is a fundamentally nonlinear process, the occurrence of turbulence in the channel can be simply understood in terms of an alternating enhancement and suppression of nearbottom tidal flows in the channel by the subinertial trapped wave. As the tidal constituents do not have frequencies that are exact multiples of one another, we expect that their relative phases will drift on a slow time scale, and this can be seen both in the observed and modeled mooring time series (Fig. 2b). At the beginning of the time series the daily inequality is large as the constituents are in phase, and lee waves are alternately enhanced and suppressed in the channel. However, near the end of the time series the inequality is much reduced, and the baroclinic structure of flows through the channel is much more similar in adjacent tides.

\section{c. Diurnal trapped waves and regional energetics}

In this section we examine the energetics of the baroclinic tides in each of the simulations, with a goal of understanding the influence of the subinertial tide on the overall tidal energetics of the region. We define depth mean, barotropic components using upper case variables:

$$
\mathbf{U}=\frac{1}{H} \int_{-H}^{0} \mathbf{u} d z=\frac{1}{H} \overline{\mathbf{u}}
$$

where $H$ is the fluid depth and the overbar indicates a depth integral. The baroclinic components (indicated with primes) are simply the depth dependent components of the flow, such that

$$
\begin{aligned}
& \mathbf{u}(x, y, z, t)=\mathbf{U}(x, y, t)+\mathbf{u}^{\prime}(x, y, z, t) ; \\
& p(x, y, z, t)=P(x, y, t)+p^{\prime}(x, y, z, t),
\end{aligned}
$$

where $\mathbf{u}$ is the velocity and $p$ is the pressure (see, e.g., Nash et al. 2005). Following the framework of Kang and Fringer (2012), the depth-integrated baroclinic energy equation becomes

$$
\frac{\partial}{\partial t}\left(\overline{E_{p}^{\prime}}+\overline{E_{k}^{\prime}}\right)+\nabla_{H} \cdot \overline{\mathbf{F}^{\prime}}=\bar{C}-\overline{\epsilon^{\prime}},
$$


where $E_{p}^{\prime}$ and $E_{k}^{\prime}$ are the baroclinic available potential and kinetic energies, respectively; $\mathbf{F}^{\prime}$ is the baroclinic energy flux; $\nabla_{H}$. indicates horizontal divergence; $C$ is the conversion of barotropic to baroclinic energy; and $\epsilon^{\prime}$ is the dissipation rate of baroclinic energy. We approximate $E_{p}^{\prime}$ by the linear available potential energy,

$$
E_{p}^{\prime}=\frac{1}{2} \frac{g^{2} \rho^{2}}{N^{2} \rho_{0}},
$$

where $g$ is the gravitational acceleration, $\rho^{\prime}$ is the density anomaly with respect to the background (tidal mean) stratification, $N^{2}$ is the tidal mean BruntVäisälä frequency, and $\rho_{0}$ is the reference density. This expression is accurate for a linear background stratification, but may become inaccurate in the presence of nonlinear waves or strongly varying stratification (Kang and Fringer 2010). Baroclinic kinetic energy is

$$
E_{k}^{\prime}=\frac{1}{2} \rho_{0}\left(u^{2}+v^{\prime 2}+w^{\prime 2}\right),
$$

where $\left(u^{\prime}, v^{\prime}, w^{\prime}\right)$ represent baroclinic velocity components in each direction. The baroclinic energy flux $\mathbf{F}^{\prime}$ is

$$
\begin{aligned}
\mathbf{F}^{\prime}= & \overline{\mathbf{u}_{H} E_{k}^{\prime}}+\overline{\mathbf{u}_{H} E_{k 0}^{\prime}}+\overline{\mathbf{u}_{H} E_{p}^{\prime}}+\overline{\mathbf{u}^{\prime} p^{\prime}} \\
& -\overline{\nu_{H} \nabla_{H} E_{k}^{\prime}}-\overline{\kappa_{H} \nabla_{H} E_{p}^{\prime}},
\end{aligned}
$$

where $E_{k 0}^{\prime}=\rho_{0}\left(U u^{\prime}+V v^{\prime}\right)$ is the barotropic-baroclinic kinetic energy cross term (the depth integral of which is zero) and subscript $H$ indicates the horizontal components of the velocity. The first three flux terms account for the advection of energy by the flow, which are elevated where a time mean flow advects time mean energy in the domain, or where eddy correlations between energy fluctuations and velocities generate an eddy flux. These advection terms are generally small in our simulations. The pressure work term $\overline{\mathbf{u}^{\prime} p^{\prime}}$ accounts for energy fluxes by waves and is a leading term in our balances. Over nonflat topography regions of the domain, the baroclinic flux computed using the baroclinic pressure defined above includes small contributions from the surface tide due to isopycnal heave (Kelly et al. 2010). We compute fluxes associated with each tidal constituent separately by performing a harmonic fit of velocity and pressure to the $K_{1}$ and $M_{2}$ tidal frequencies, then calculating the flux associated with reconstructed time series for each constituent. The last two terms in Eq. (7) represent viscous and diffusive fluxes and are negligible in our simulations.

The rate at which barotropic energy is converted to baroclinic energy is represented by the conversion, and here we consider only the linear part of this term:

$$
\bar{C}=\rho^{\prime} g W,
$$

where $W$ is the barotropic vertical velocity arising from the convergence of horizontal barotropic flows. It linearly decreases in magnitude from the bottom (located at $z=-H)$ to the surface:

$$
W=-\nabla_{H} \cdot\left[(H+z) U_{H}\right] .
$$

In our simulations, explicit baroclinic turbulent dissipation $\epsilon^{\prime}$ is calculated as the sum of the vertical component of the Laplacian dissipation $\epsilon_{v}=\rho_{0} \nu_{\mathrm{KL}}\left|\partial_{z} \mathbf{u}\right|^{2}$ [where $\nu_{\mathrm{KL}}$ is determined by the Klymak and Legg (2010) parameterization], the horizontal Laplacian dissipation $\epsilon_{H}=\rho_{0} \nu_{H}\left|\nabla_{H} \mathbf{u}\right|^{2}$, and the dissipation by the quadratic bottom drag $\epsilon_{D}=\rho_{0} C_{d}\left|\mathbf{u}_{H}\right|\left(u u^{\prime}+v v^{\prime}+w^{\prime 2}\right)$ at $z=-H$.

In what follows, we consider regionally integrated and temporally averaged values of Eq. (4), estimated from hourly snapshot output of the modeled fields. Time averaging is performed over tidal periods, once the simulation has spun up and is close to steady state. Averaging periods for the $\mathrm{M}_{2}$-only simulation are: $25 \mathrm{~h}$ from 125 to $150 \mathrm{~h}$ for the $\mathrm{K}_{1}$-only simulation, $48 \mathrm{~h}$ from 96 to $144 \mathrm{~h}$ for the $\mathrm{K}_{1}$-only simulation, and $25 \mathrm{~h}$ from 311 to $336 \mathrm{~h}$ for the $\mathrm{K}_{1}+\mathrm{M}_{2}$ simulation (the $\mathrm{K}_{1}$ flux in this simulation was calculated over $24 \mathrm{~h}$ ). The regional integral is performed over the vicinity of the ridge: $100<x<145 \mathrm{~km}$ and $100<y<140 \mathrm{~km}$ (see Fig. 1). In each of the three simulations, the dominant terms were the pressure work, barotropic to baroclinic conversion, and dissipation rates. Nonlinear fluxes are $1 \%, 3 \%$, and $6 \%$ of the pressure work in the $\mathrm{K}_{1}$-only, $\mathrm{M}_{2}$-only, and $\mathrm{K}_{1}+\mathrm{M}_{2}$ simulations, respectively, indicating a small but increasing role for nonlinear fluxes with increased tidal amplitude. Time and regional averages of the total outward flux (pressure work + nonlinear flux), conversion, and dissipations for each of the simulations are shown in Table 1. Using these terms to estimate Eq. (4) integrated over the region results in a residual, or error term, that arises mainly from a combination of numerical diffusion in the model and errors in our offline calculation of the terms (both due to difficulties in evaluating energy terms on a $\mathrm{C}$ grid and from the limited temporal resolution of our data). Small errors are also expected from our neglect of the nonlinear terms in the energy equations. Mixing in the model contributes to small nonzero time-dependent terms, as the stratification is gradually eroded over the course of the run. Together, the sum of these error and the time-dependent terms account for less than $15 \%$ of the conversion term 
TABLE 1. Terms of baroclinic energy budget (MW) for each simulation, integrated over analysis domain. The local dissipation efficiency is estimated using both the explicit and inferred dissipation rates in the region ( $q_{e}$ and $q_{i}$, respectively).

\begin{tabular}{lccc}
\hline \hline & $\mathrm{K}_{1}$-only & $\mathrm{M}_{2}$-only & $\mathrm{K}_{1}+\mathrm{M}_{2}$ \\
\hline $\bar{C}$ & 58 & 211 & 275 \\
$\nabla_{H} \cdot \overline{\mathbf{F}}^{\prime}$ & 12 & 153 & 142 \\
$\overline{\epsilon_{e}}$ & 35 & 45 & 81 \\
$q_{e}$ & $60 \%$ & $21 \%$ & $29 \%$ \\
$\overline{\epsilon_{i}}$ & 43 & 39 & 123 \\
$q_{i}$ & $74 \%$ & $18 \%$ & $45 \%$ \\
\hline
\end{tabular}

across all simulations. For both the $\mathrm{K}_{1}$-only and the $\mathrm{K}_{1}+\mathrm{M}_{2}$ simulations, the residual had a sign consistent with an underestimation of the explicit dissipation $\epsilon_{e}$ in the model. Assuming that the dominant source of error in the budget arises from numerical diffusion, we define an "inferred dissipation rate" $\epsilon_{i}$ to be the sum of the explicit dissipation rate and the residual. In a sensitivity study of a similar regional tidal model $(\approx 80 \mathrm{~m}$ horizontal resolution, $\nu_{H}=1 \mathrm{~m}^{2} \mathrm{~s}^{-1}, \nu_{v}=5 \times 10^{3} \mathrm{~m}^{2} \mathrm{~s}^{-1}$ using a high-resolution total variation diminishing scheme with the superbee limiter for density advection), Kang and Fringer (2012) find that their inferred dissipation rate is insensitive to turbulence closure parameters in a regional numerical simulation at Monterey Canyon, and in that sense is a more reliable estimate of the energy dissipation in the model than the explicitly calculated dissipation. The residual of the $\mathrm{M}_{2}$-only simulation was surprisingly small, only $3 \%$, and with a sign that indicated an underestimation of the conversion or an overestimation of the outward flux. In this case the temporal resolution of this simulation is relatively worse than the others, with only 12 output snapshots per period, and the errors associated with the poorer time resolution are relatively larger, dominating the error from numerical diffusion and changing the sign of the expected residual term.

\section{1) Flux, CONVERSION, AND DISSIPATION}

Maps of time-averaged conversion, $\mathrm{M}_{2}$-flux, $\mathrm{K}_{1}$-flux, and dissipation rate from the $\mathrm{K}_{1}+\mathrm{M}_{2}$ simulation are shown in Fig. 5a.

Modeled conversion is elevated close to the crest of the ridge, where the internal tide is most efficiently generated at a rate of up to $1.5 \mathrm{~W} \mathrm{~m}^{-2}$. For comparison, Kang and Fringer (2012) calculate conversions of around $0.2 \mathrm{~W} \mathrm{~m}^{-2}$ at Monterey Canyon, while Carter et al. (2008) obtain $1-2 \mathrm{~W} \mathrm{~m}^{-2}$ at the Hawaiian Ridge (a deep ocean site), and Buijsman et al. (2014) calculate peak conversions of $1.5 \mathrm{~W} \mathrm{~m}^{-2}$ at the Luzon Strait. Regions of negative conversion north of the crest arise from the interaction of internal tide energy that was generated at the crest and interacts with barotropic convergence along the shelf break, leading to a negative correlation between the density anomaly and local barotropic flow convergence. Eel Canyon, located to the north of the ridge around $y=160 \mathrm{~km}$, $x=130 \mathrm{~km}$, exhibits a complex pattern of conversion between barotropic and baroclinic tidal energy as local generation in the canyon is influenced by the energy fluxed northward from the ridge.

The distinct natures of the baroclinic $\mathrm{K}_{1}$ and $\mathrm{M}_{2}$ constituents are made clear in Figs. 5b and 5c, which show the flux associated with each frequency. Fluxes of the $\mathrm{M}_{2}$ constituent are directed outwards from the crest and mostly toward deeper water, except along the shelf break to the north of the crest where energy is refracted along the shelf break and into the two canyons. Our modeled up-canyon fluxes are consistent with observations from Eel Canyon, which indicates that most of the energy incident at the mouth of the canyon is dissipated along its length (Waterhouse et al. 2017). $\mathrm{M}_{2}$ fluxes in our simulation are large, reaching up to $7.5 \mathrm{~kW} \mathrm{~m}^{-2}$ in places close to the crest of the ridge.

In contrast to the $\mathrm{M}_{2}$ flux that shows energy radiating away from the ridge in much of the modeled domain, the $\mathrm{K}_{1}$ flux is much smaller and more regionally confined. Flux arrows tend to parallel bathymetric contours, mostly westward to the south of the crest and eastward to the north, consistent with a trapped wave propagating with shallow water to the right. Regions of flux convergence along isobaths are evident both to the south of the ridge at depth $(x=60 \mathrm{~km}, y=80 \mathrm{~km})$ and in the vicinity of the ridge crest and canyon. Elevated dissipation is associated with these regions, indicating a loss of energy from the trapped internal tide to small scales at these sites (Fig. 5d, and also Fig. 7b). These dissipations are associated with both a topographic "corner" and a change in the bathymetric slope, essentially constituting an abrupt change in the topographic waveguide. Trapped wave fluxes are largest to the north of the ridge where the trapped wave closely resembles an internal Kelvin wave along the steep bathymetry.

Time-averaged dissipation rates from the viscous Laplacian terms, $\epsilon_{H}+\epsilon_{v}$, are shown in Fig. 5d. Dissipation of baroclinic energy by bottom drag is an order of magnitude smaller than from Laplacian viscosity and can locally be negative where the barotropic and bottom baroclinic velocities have opposite sign (dissipation by this term is, however, positive over regional integrals). Dissipation from horizontal shear $\left(\epsilon_{H}\right)$ is smaller but a similar magnitude than from vertical shear $\left(\epsilon_{v}\right)$ in all simulations. Dissipation of baroclinic energy is 


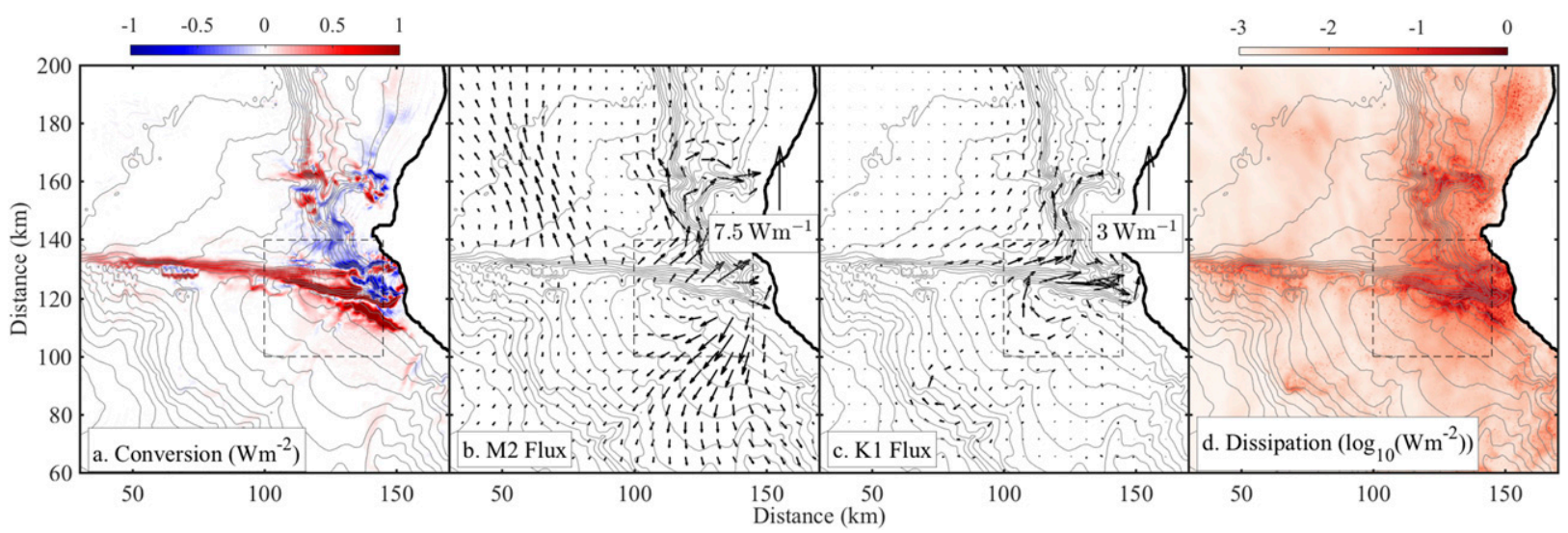

FIG. 5. Regional energy budget terms for the $K_{1}+M_{2}$ simulation: (a) barotropic-baroclinic conversion, (b) $M_{2}$ flux, (c) $K_{1}$ flux, and (d) time-averaged dissipation rate. Note different scales for flux vectors for each constituent. Dashed box indicates analysis region for terms quoted in Table 1.

enhanced close to the crest of the ridge, in particular along the flanks where tidal lee waves form (M16). Inhomogeneities in dissipation rate along the length of the ridge reflect small-scale bathymetric complexity, with enhanced dissipation occurring close to the channel at the ridge crest and at other small-scale features. Dissipation is also enhanced in Eel Canyon, a site of $\mathrm{M}_{2}$ and $\mathrm{K}_{1}$ flux convergence. In situ observations indicate that the $\mathrm{M}_{2}$ internal tide sets up a partially standing wave in the canyon, as energy incident from the ridge to the south reflects from the head of the canyon, leading to elevated dissipation along the length of the canyon (Waterhouse et al. 2017). Dissipation high in the water column is semidiurnally modulated and associated with the $\mathrm{M}_{2}$ constituent, while dissipation along the bottom is diurnally modulated and associated with the $\mathrm{K}_{1}$ constituent.

\section{2) THE INFLUENCE OF SUbineRTIAL $\mathrm{K}_{1}$ ON THE LOCAL DISSIPATION EFFICIENCY $q$}

Following St. Laurent et al. (2002), we define a "local dissipation efficiency" $q$ such that the dominant terms of the time-averaged baroclinic energy equation [Eq. (4)] is

$$
q \approx 1-\frac{\nabla_{H} \cdot \overline{\mathbf{F}^{\prime}}}{\bar{C}}
$$

As such, the local dissipation efficiency $q$ defines the fraction of the energy converted into baroclinic motions that is dissipated locally, contributing to near-field mixing and water mass modification. The remaining baroclinic energy radiates into the far field to effect mixing at remote locations, either via nonlinear interactions in the open ocean, or by shoaling on far topography (in our regional simulation, most of this energy is dissipated in sponge regions, well outside of our analysis region). The values of the most energetically important terms integrated over the analysis region (dashed box in Fig. 5), and the derived $q$ for each simulation is shown in Table 1.

Unsurprisingly, the $\mathrm{K}_{1}$-only simulation has the highest fraction of locally dissipated baroclinic energy as trapped waves generated at the ridge crest do not propagate efficiently out of the domain to the north. Trapped waves are eigenmodes of the bathymetry where they are generated. However, as they propagate away from their generation site along irregular bathymetry, they encounter changing topography and small scales, leading to large dissipation rates. As such, most (at least $60 \%$ ) of the baroclinic energy generated by this subinertial $\mathrm{K}_{1}$ tide is dissipated very close to where it is generated (within the analysis region), while the rest propagates northward along the shelf break.

In contrast, the $\mathrm{M}_{2}$-only simulation has the lowest fraction of locally dissipated baroclinic energy, as baroclinic waves generated by the topography efficiently radiate into the open ocean and out of the domain. In our analysis domain, around $21 \%$ of the generated baroclinic energy is dissipated in the near field, through near-ridge processes such as tidal lee waves and hydraulic jumps.

Including both constituents in a single simulation changes the regional energy balance in a complicated manner. Over the region of this analysis, both conversion and dissipation are slightly larger in the $\mathrm{K}_{1}+\mathrm{M}_{2}$ simulation than the sum of the individual constituent runs, and both the inferred and explicit dissipation is increased over the individual constituent 


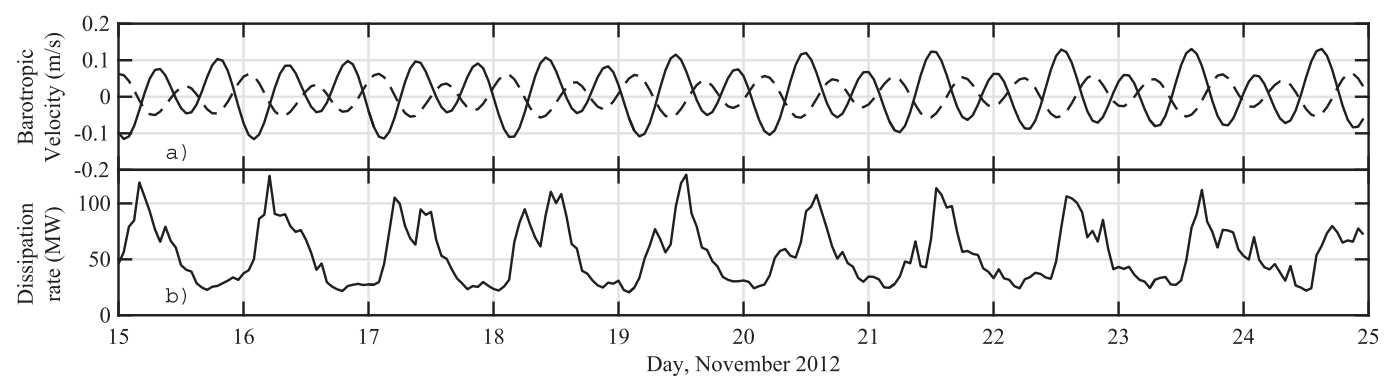

FIG. 6. Time series of (a) area-averaged barotropic tidal speeds (solid, cross-ridge velocity; dashed, along-ridge velocity) and (b) volume-integrated dissipation rates for $100<x<145 \mathrm{~km}$ and $100<y<140 \mathrm{~km}$.

runs. This is particularly notable in the inferred dissipation rate $\overline{\epsilon_{i}}$, which shows an increase of about 3 times over the sum of individual constituent runs, suggesting that the larger tides in the $\mathrm{K}_{1}+\mathrm{M}_{2}$ simulation generated flows that were relatively less well resolved (i.e., at smaller scales), causing the numerical scheme to dissipate a larger fraction of the unresolved variance. The local dissipation efficiency in the two constituent runs is $45 \%$, compared to Monterey Canyon, where Kang and Fringer (2012) used a numerical simulation to find that $58 \%$ of baroclinic $\mathrm{M}_{2}$ energy dissipates locally, and at the Luzon Strait, where Alford et al. (2015) used observations to estimate $q=40 \%$. At deep ocean sites, such as Hawaii, radiation is much larger than dissipation, and Carter et al. (2008) estimate $q=15 \%$.

\section{3) THE TIMING AND STRUCTURE OF DISSIPATION AT THE CREST OF THE RIDGE}

Time series of the simulated volume-integrated dissipation rates and area-averaged barotropic tidal speeds for the vicinity of the ridge $(100<x<145 \mathrm{~km}$ and $100<y<$ $140 \mathrm{~km})$ are shown in Fig. 6 . In this region, the $\mathrm{M}_{2}$ constituent has an averaged cross-ridge barotropic amplitude of $0.09 \mathrm{~m} \mathrm{~s}^{-1}$, while the $\mathrm{K}_{1}$ constituent has an averaged cross-ridge barotropic amplitude of $0.04 \mathrm{~m} \mathrm{~s}^{-1}$. Strikingly, despite the semidiurnal barotropic tide having more than double the amplitude of the diurnal tide, the volumeintegrated dissipation rate is diurnal, varying by an order of magnitude once per day. In the first part of the time series, peak dissipation rates occur just after peak southward flow, which is the largest of the daily peaks. As the relative timing of the tidal peaks associated with the $\mathrm{K}_{1}$ and $\mathrm{M}_{2}$ constituents progress over the course of the simulation, the largest tidal speeds become associated with northward flow, and consequently the dissipation peak shifts to lag the peak northward flow.

Observed time series from stations over the ridge on the western flank of the channel [R1 and R2, Fig. 1b(i)] show similar features to the time series in the channel, with alternate northward flows being surface confined and not generating tidal lee waves. Combined with these model results, we conclude that the specific interaction of the two tidal constituents described for the channel flows in section $4 \mathrm{~b}$ is relevant over the whole ridge crest region, that is, the generation of tidal lee waves and near-field turbulence is entirely determined by the constructive superposition of the nontrapped $\mathrm{M}_{2}$ and trapped $\mathrm{K}_{1}$ wave.

Vertical profiles of regionally averaged dissipation rates in all simulations exhibit enhancement by an order of magnitude between 0 and $250 \mathrm{~m}$ height above bottom (Fig. 7a). Despite the barotropic amplitude of the $\mathrm{K}_{1}$ tide being half of that of the $\mathrm{M}_{2}$ tide in the analysis region, dissipation rates near the bottom are comparable, as the bottom-trapped tide displays a greater tendency to dissipation than the superinertial tide. However, dissipation in the $\mathrm{K}_{1}$-only simulation decays by two orders of magnitude close to the surface where velocities associated with the trapped tide are small, in contrast with dissipations in the $\mathrm{M}_{2}$-only, which is relatively elevated well above the bottom.

Maps of the depth-integrated dissipation rates in each of the $\mathrm{K}_{1}$-only and $\mathrm{M}_{2}$-only simulations exhibit enhanced dissipation at the crest of the ridge and along the bathymetry between the ridge and Eel Canyon to the north. Consistent with the subinertial tide being topographically trapped, dissipation for this constituent is localized near bathymetric slopes, in contrast to dissipation in the $\mathrm{M}_{2}$-only simulation, which is significant even over regions of flat topography. In particular, the subinertial constituent exhibits dissipation where the topographic slope changes in the along-bathymetric direction, or where small-scale features such as gullies and corners are present, indicating that trapped wave energy is not efficiently transmitted around these changes.

\section{d. Time mean flows}

The combined influences of friction, nonlinearity, and rotation can lead to the rectification of tidal flows over 

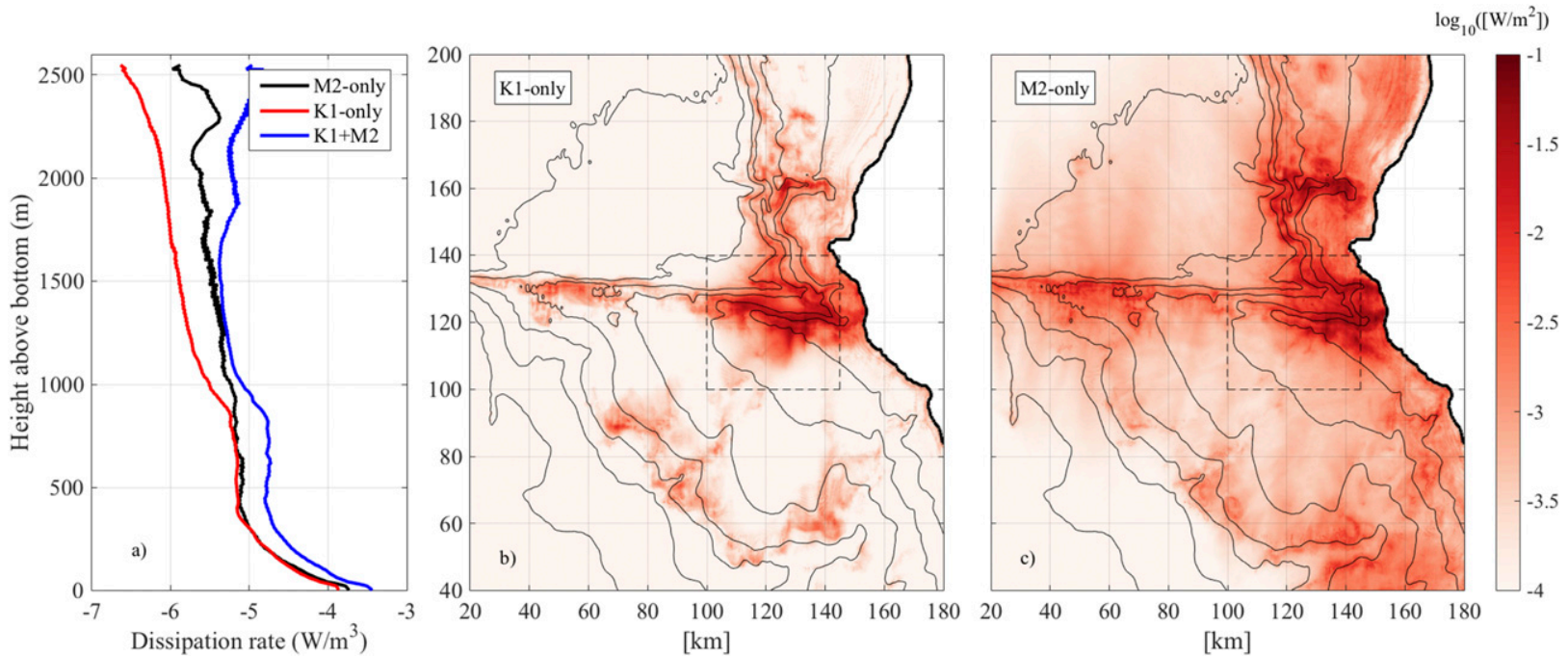

FIG. 7. (a) Vertical profiles of time and spatially averaged dissipation rates within the analysis region for each simulation $(100<x<$ $145 \mathrm{~km}$ and $100<y<140 \mathrm{~km}$ ). The amplitude of the $\mathrm{K}_{1}$ barotropic velocity is half that of the $\mathrm{M}_{2}$, yet the dissipation rate close to the bottom is comparable. (b),(c) Maps of depth-integrated, time-averaged dissipation rates for the $\mathrm{K}_{1}$-only and $\mathrm{M}_{2}$-only simulations.

sloping topography, generating geostrophically balanced time mean flows along isobaths with shallow water to their right in the Northern Hemisphere (e.g., Huthnance 1973; Maas and Zimmerman 1989; Musgrave et al. 2016b). Regions of mixed fluid close to the ridge will also lead to geostrophically balanced jets (Chen et al. 1995). Significant time mean transports occur in each of the simulations, in particular in the vicinity of the ridge (Fig. 8). The boundary conditions imposed at the edges of the numerical domain prevent time mean flows passing through the boundaries and may be responsible for restricting the appearance of rectified flows in our simulations to closed circulations and isolated topographic contours. Two rectified eddies are formed in the simulations, the largest to the north of the ridge having time mean barotropic speeds of up to $0.15 \mathrm{~m} \mathrm{~s}^{-1}$. These time mean, tidally driven eddies are an intrinsic component of tidal interaction with the complex topography in the region and may play a role in the lateral spreading of water masses mixed and modified by tidal processes at the ridge crest, into the ocean's interior, and the restratification of mixed fluid at the boundary.

\section{Summary}

Observations in the vicinity of a channel through the Mendocino Ridge show that tidal lee waves are only generated once per day, despite the twice daily tidal peaks. Tidal lee waves form only after the largest peak tide each day (the strong beat of the tide), with nearbottom currents and lee wave formation suppressed during the weaker peak tide. In this paper we have used regional tide simulations of the region to interpret these observations in terms of subinertial internal tide dynamics.

Using a regional model driven by TPXO barotropic tides at the boundaries, we show that the subinertial tidal constituent generates a trapped wave that propagates anticyclonically around the ridge crest and generates large transports through the channel. This subinertial trapped wave is locally dissipative, with our single constituent ( $\mathrm{K}_{1}$-only) simulation showing that at least $60 \%$ of the energy converted from barotropic to baroclinic motions are dissipated close to where the wave is generated. This is consistent with maps of barotropic tidal dissipation made by Egbert and Ray (2003), who show that this location is an efficient dissipator of $\mathrm{K}_{1}$ barotropic tidal energy. With this work we suggest that trapped internal tides play an important role in that energy pathway.

The large, bottom-trapped isopycnal displacements and velocities associated with the trapped wave cause near-bottom flows through the channel to be alternately enhanced and suppressed depending on whether the bottom trapped wave constructively superposes with the semidiurnal tide or not. When both constituents are in the same direction, the flow through the channel is bottom intensified and generates a large, turbulent tidal lee wave on the downstream face of the ridge. When the constituents have opposite directions, the bottom flows associated with the trapped wave cancel the flows associated with the semidiurnal tide at depth, so that even though the semidiurnal tide has a larger 


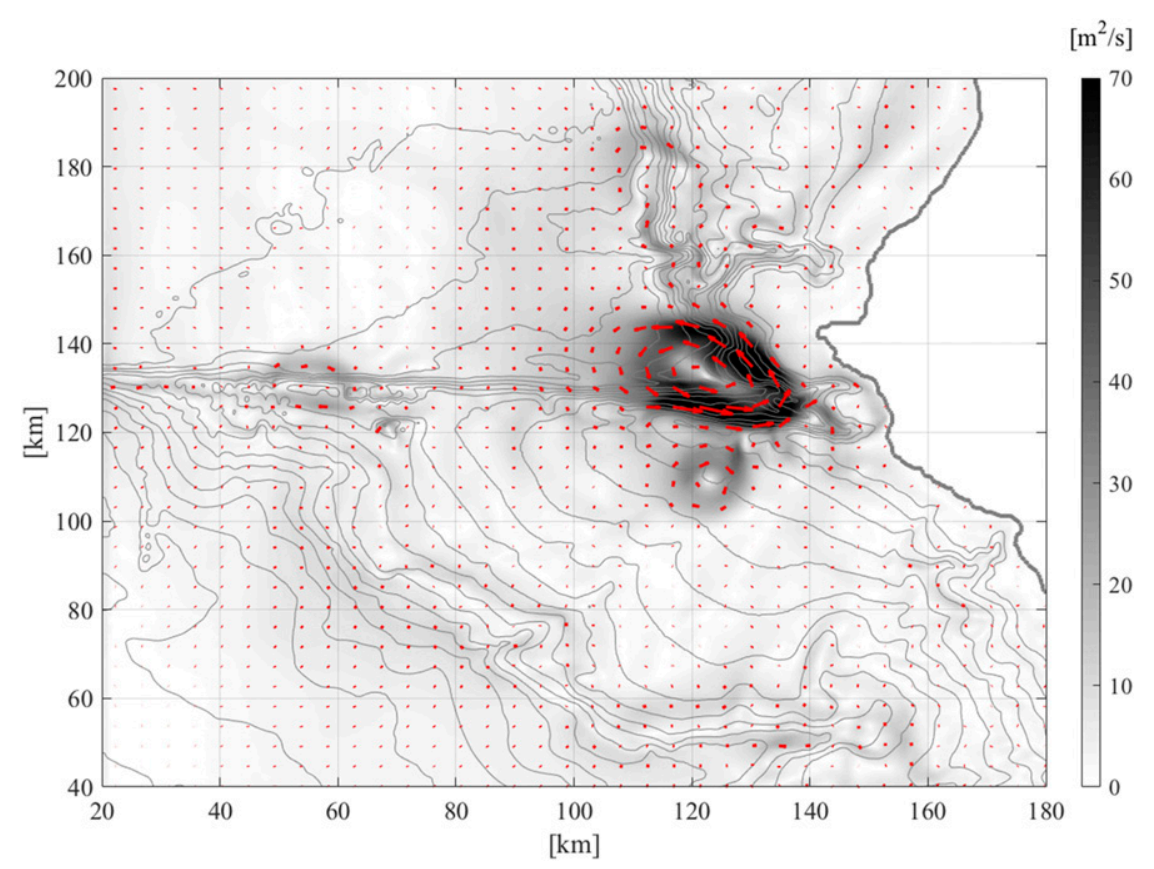

FIG. 8. Time mean depth-integrated transport (grayscale) and direction (arrows) in $\mathrm{K}_{1}+\mathrm{M}_{2}$ simulation. Tidally rectified flows form close to topography and have velocities of up to $0.15 \mathrm{~m} \mathrm{~s}^{-1}$.

volume transport, it is accommodated close to the surface and does not interact directly with the ridge. In this latter case, no tidal lee wave forms and turbulent dissipation rates are small, despite there being a net cross-ridge flow.

The extent to which this process in the channel is applicable to the rest of the ridge is assessed using the model to consider ridge-averaged quantities. Over the 10-day simulation, ridge-averaged turbulent dissipation rates are diurnally modulated, despite average barotropic velocities being dominantly semidiurnal. Observations from atop the crest of the ridge flanking the channel show similar baroclinic structures as within the channel, and we infer that the specific process described for the channel flows is more generally relevant over this ridge.

Modeled dissipation of the trapped wave also arises independently of the superinertial tidal constituent, in regions of varying along-isobath topography. These regions effectively constitute changes to the topographic waveguide, influencing the efficiency with which energy can be fluxed along the shelf. Furthermore, the nature of these bottom-trapped waves is such that they are extremely dissipative via boundary layer processes and interactions with small topographic features.

At this location, therefore, we conclude that the subinertial trapped wave strongly influences the near-field dissipation rate and its concomitant mixing, having broader implications on water mass properties and regional-scale flows. Vertical profiles of the modeled dissipation rate indicate that close to the bottom, dissipation in the $\mathrm{K}_{1}$-only simulation is comparable to dissipation in the $\mathrm{M}_{2}$-only simulation, again, despite the depth mean currents associated with the $\mathrm{K}_{1}$ constituent being half of those associated with the $\mathrm{M}_{2}$ constituent. The bottomtrapped nature of the subinertial trapped wave makes it much more dissipative even at smaller amplitude than the radiating superinertial internal tide. The subinertial bottom-trapped wave has a high local dissipation efficiency $q$ with only a small flux of energy escaping the region to radiate up along the shelf. Maps of the depthintegrated dissipation rate indicate that dissipation associated with the subinertial constituent is intense, and much more localized close to regions of steep topography than with the superinertial constituent, which exhibits dissipation far away from the ridge.

The generation of time mean flows by the tides in our simulations is significant, with time mean, depth mean speeds of up to $0.15 \mathrm{~m} \mathrm{~s}^{-1}$ in some regions. In this region of complex, three-dimensional bathymetry, rectified flows take the form of closed, standing eddies, effectively enhancing the lateral diffusivity of the region by advecting mixed fluid away from the near-ridge region, while restratifying the fluid close to the crest. These standing eddies may play an important role 
in communicating water mass modification at the boundaries with the ocean's interior.

In summary, we find that the influence of subinertial tidal constituents on the distribution of dissipation and mixing in this region is significant. Generalizing to other regions, our study suggests that mixing by subinertial tides may be globally significant, the impacts of their mixing being especially important in climactically sensitive regions where the vertical redistribution of heat can directly affect the formation and melt of sea ice, or the basal erosion of glaciers. Furthermore, understanding the processes leading to tidally driven turbulence and mixing at latitudes where the diurnal tide is subinertial $\left(>30^{\circ}, 50 \%\right.$ of the Earth's surface) requires consideration of both the subinertial and superinertial tidal constituents, with subinertial bottom velocities determining both the magnitude and timing of neartopographic dissipation rates.

Acknowledgments. Ship time was provided by the University of California Ship Funds. Shaun Johnston, Uwe Send, and Janet Sprintall generously loaned instrumentation that made these measurements possible. Thanks to Capt. Murline and the crew of the R/V Melville for their professionalism at sea; Paul Chua for his engineering expertise; and Julie Alvarez, Hanne Beate Skator, Elizabeth Bunin, Vanessa Crandall-Beck, Jonathan Franco, Michael Fuentes, Felipe Gomez, Bob Reed, and Alfredo Wetzel for their invaluable help gathering this data. Computing was carried out on the COMPAS cluster at SIO. We gratefully acknowledge useful conversations with Myrl Hendershott and Ken Brink, and we thank Uriel Zajaczkovski for his help making the $3 \mathrm{D}$ visualizations using Paraview, an open source platform for scientific visualization. This manuscript was improved by the comments and suggestions of three anonymous referees. R.C.M. was supported by the Office of Naval Research. A.F.W. was supported by NSF OCE-0968721. J.A.M. was supported by ONR-N00014-091-0273.

\section{REFERENCES}

Alford, M. H., and Coauthors, 2015: The formation and fate of internal waves in the South China Sea. Nature, 521, 65-69, doi:10.1038/nature14399.

Brink, K. H., 1989: The effect of stratification on seamount-trapped waves. Deep-Sea Res., 36A, 825-844, doi:10.1016/0198-0149 (89)90031-9.

_ 1990: On the generation of seamount-trapped waves. DeepSea Res., 37A, 1569-1582, doi:10.1016/0198-0149(90)90062-Z.

Buijsman, M. C., S. Legg, and J. Klymak, 2012: Double-ridge internal tide interference and its effect on dissipation in Luzon Strait. J. Phys. Oceanogr., 42, 1337-1356, doi:10.1175/ JPO-D-11-0210.1.
- , and Coauthors, 2014: Three-dimensional double-ridge internal tide resonance in Luzon Strait. J. Phys. Oceanogr., 44, 850-869, doi:10.1175/JPO-D-13-024.1.

Carter, G. S., and M. A. Merrifield, 2007: Open boundary conditions for regional tidal simulations. Ocean Modell., 18, 194-209, doi:10.1016/j.ocemod.2007.04.003.

- , and Coauthors, 2008: Energetics of $\mathrm{M}_{2}$ barotropic-tobaroclinic tidal conversion at the Hawaiian Islands. J. Phys. Oceanogr., 38, 2205-2223, doi:10.1175/2008JPO3860.1.

Chapman, D. C., 1989: Enhanced subinertial diurnal tides over isolated topographic features. Deep-Sea Res., 36, 815-824, doi:10.1016/0198-0149(89)90030-7.

Chen, C., R. C. Beardsley, and R. Limeburner, 1995: A numerical study of stratified tidal rectification over finite-amplitude banks. Part II: Georges Bank. J. Phys. Oceanogr., 25, 2111-2128, doi:10.1175/1520-0485(1995)025<2111:ANSOST>2.0.CO;2.

Daru, V., and C. Tenaud, 2004: High order one-step monotonicitypreserving schemes for unsteady compressible flow calculations. J. Comput. Phys., 193, 563-594, doi:10.1016/ j.jcp.2003.08.023.

Egbert, G. D., and S. Y. Erofeeva, 2002: Efficient inverse modeling of barotropic ocean tides. J. Atmos. Oceanic Technol., 19, 183-204, doi:10.1175/1520-0426(2002)019<0183:EIMOBO>2.0.CO;2.

, and R. D. Ray, 2003: Semi-diurnal and diurnal tidal dissipation from TOPEX/Poseidon altimetry. Geophys. Res. Lett., 30, 1907, doi:10.1029/2003GL017676.

Farmer, D. M., and J. D. Smith, 1980: Tidal interaction of stratified flow with a sill in Knight Inlet. Deep Sea Res., 27A, 239-254, doi:10.1016/0198-0149(80)90015-1.

Green, J. A. M., and J. Nycander, 2013: A comparison of tidal conversion parameterizations for tidal models. J. Phys. Oceanogr., 43, 104-119, doi:10.1175/JPO-D-12-023.1.

Huthnance, J. M., 1973: Tidal current asymmetries over the Norfolk sandbanks. Estuarine Coastal Mar. Sci., 1, 89-99, doi:10.1016/0302-3524(73)90061-3.

_ 1974: On the diurnal tidal currents over Rockall Bank. DeepSea Res. Oceanogr. Abstr., 21, 23-35, doi:10.1016/0011-7471 (74)90016-3.

Kang, D., and O. B. Fringer, 2010: On the calculation of available potential energy in internal wave fields. J. Phys. Oceanogr., 40, 2539-2545, doi:10.1175/2010JPO4497.1.

— and - 2012: Energetics of barotropic and baroclinic tides in the Monterey Bay area. J. Phys. Oceanogr., 42, 272-290, doi:10.1175/JPO-D-11-039.1.

Kelly, S. M., J. D. Nash, and E. Kunze, 2010: Internal-tide energy over topography. J. Geophys. Res., 115, C06014, doi:10.1029/ 2009JC005618.

Klymak, J., and S. Legg, 2010: A simple mixing scheme for models that resolve breaking internal waves. Ocean Modell., 33, 224-234, doi:10.1016/j.ocemod.2010.02.005.

— - and Coauthors, 2006: An estimate of tidal energy lost to turbulence at the Hawaiian Ridge. J. Phys. Oceanogr., 36, 1148-1164, doi:10.1175/JPO2885.1.

- R. Pinkel, and L. Rainville, 2008: Direct breaking of the internal tide near topography: Kaena Ridge, Hawaii. J. Phys. Oceanogr., 38, 380-399, doi:10.1175/2007JPO3728.1.

— S. Legg, and R. Pinkel, 2010: High-mode stationary waves in stratified flow over large obstacles. J. Fluid Mech., 644, 321-336, doi:10.1017/S0022112009992503.

Kunze, E., and J. M. Toole, 1997: Tidally driven vorticity, diurnal shear, and turbulence atop Fieberling Seamount. J. Phys. Oceanogr., 27, 2663-2693, doi:10.1175/1520-0485(1997)027<2663: TDVDSA $>2.0 . \mathrm{CO} ; 2$. 
Maas, L. R. M., and J. T. F. Zimmerman, 1989: Tide-topography interactions in a stratified shelf sea. I. Basic equations for quasi-nonlinear internal tides. Geophys. Astrophys. Fluid Dyn., 45, 1-36, doi:10.1080/03091928908208891.

Marshall, J., A. Adcroft, C. Hill, L. Perelman, and C. Heisey, 1997: A finite-volume, incompressible Navier Stokes model for studies of the ocean on parallel computers. J. Geophys. Res., 102, 5753-5766, doi:10.1029/96JC02775.

Martini, K. I., M. H. Alford, E. Kunze, S. M. Kelly, and J. D. Nash, 2011: Observations of internal tides on the Oregon continental slope. J. Phys. Oceanogr., 41, 1772-1794, doi:10.1175/ 2011JPO4581.1.

Müller, M., 2013: On the space-and time-dependence of barotropic-to-baroclinic tidal energy conversion. Ocean Modell., 72, 242-252, doi:10.1016/j.ocemod.2013.09.007.

Musgrave, R. C., J. A. MacKinnon, R. Pinkel, A. F. Waterhouse, and J. D. Nash, 2016a: Tidally driven processes leading to near-field turbulence in a channel at the crest of the Mendocino Escarpment. J. Phys. Oceanogr., 46, 1137-1155, doi:10.1175/JPO-D-15-0021.1.

_, R. Pinkel, J. A. MacKinnon, M. Mazloff, and W. R. Young, 2016b: Stratified tidal flow over a tall ridge above and below the turning latitude. J. Fluid Mech., 793, 933-957, doi:10.1017/ jfm.2016.150.

Nakamura, T., Y. Isoda, H. Mitsudera, S. Takagi, and M. Nagasawa, 2010: Breaking of unsteady lee waves generated by diurnal tides. Geophys. Res. Lett., 37, L04602, doi:10.1029/ 2009 GL041456.

Nash, J. D., M. H. Alford, and E. Kunze, 2005: On estimating internal-wave energy fluxes in the ocean. J. Atmos. Oceanic Technol., 22, 1551-1570, doi:10.1175/JTECH1784.1.

Padman, L., A. J. Plueddemann, R. D. Muench, and R. Pinkel, 1992: Diurnal tides near the Yermak Plateau. J. Geophys. Res., 97, 12 639-12 652, doi:10.1029/92JC01097.

Rhines, P. B., 1970: Edge-, bottom-, and Rossby waves in a rotating stratified fluid. Geophys. Astrophys. Fluid Dyn., 1, 273-302, doi:10.1080/03091927009365776.

St. Laurent, L. C., H. L. Simmons, and S. R. Jayne, 2002: Estimating tidally driven mixing in the deep ocean. Geophys. Res. Lett., 29, 2106, doi:10.1029/2002GL015633.

Tanaka, T., I. Yasuda, Y. Tanaka, and G. S. Carter, 2013: Numerical study on tidal mixing along the shelf break in the Green Belt in the southeastern Bering Sea. J. Geophys. Res. Oceans, 118, 6525-6542, doi:10.1002/2013JC009113.

Waterhouse, A. F., J. A. MacKinnon, R. C. Musgrave, S. Kelly, A. Pickering, and J. D. Nash, 2017: Internal tide convergence and mixing in a submarine canyon. J. Phys. Oceanogr., 47, 303-322, doi:10.1175/JPO-D-16-0073.1.

Zhang, Y., and J. N. Moum, 2010: Inertial-convective subrange estimates of thermal variance dissipation rate from moored temperature measurements. J. Atmos. Oceanic Technol., 27, 1950-1959, doi:10.1175/2010JTECHO746.1. 